\section{Reply to: Gastric Cancer Prognosis: Strong Correlation Between Incidence and Survival}

\section{TO THE EDITORS:}

We extend our appreciation to Marrelli et al. for their interest in our recent publication. We are fortunate to have a melting-pot population in Los Angeles County which facilitated the demonstration of disparate gastric cancer outcomes among its four major racial and ethnic groups. ${ }^{1}$ Although we initially grouped all Asian ethnicities together, we strongly suspected that the heterogeneity in birthplace, diet, lifestyle, environmental exposures, etc., among the Asian ethnicities would influence gastric cancer outcomes.

As Marrelli et al. have indicated, Koreans have the highest gastric cancer incidence in the state of California. $^{2,3}$ Our anecdotal surgical experience that Koreans fared better than patients of other race and ethnicity has been confirmed by our recent investigation. ${ }^{4}$ This seemingly conflicting higher incidence with higher survival should also be qualified with respect to Koreans having the highest percentage of uninsured Asian residents in Los Angeles. ${ }^{5}$ These observations, therefore, suggest a unique biologic predisposition and tumor behavior which cannot be accurately assessed within the confines of this study. In this regard, we have recently initiated molecular/genetic profiling of gastric cancers by racial and ethnic groups.

Finally, we hope that our comments here and those by Marrelli et al. further highlight the need to closely examine the impact of heterogeneous racial and ethnic populations in determining the outcomes of clinical trials for gastric cancer.

Joseph Kim, MD, and Brian Mailey, MD

City of Hope Comprehensive Cancer Center and Department of Oncologic Surgery, Duarte, CA

e-mail: jokim@coh.org

Published Online: 8 October 2009

(C) Society of Surgical Oncology 2009

\section{REFERENCES}

1. Kim J, Sun CL, Mailey B, et al. Race and ethnicity correlate with survival in patients with gastric adenocarcinoma. Ann Oncol. 2009 doi:10.1093/annonc/mdp290.

2. Kwong SL, Chen MS, Jr., Snipes KP, et al. Asian subgroups and cancer incidence and mortality rates in California. Cancer. 2005;104:2975-81.

3. McCracken M, Olsen M, Chen MS Jr., et al. Cancer incidence, mortality, and associated risk factors among Asian Americans of Chinese, Filipino, Vietnamese, Korean, and Japanese ethnicities. CA Cancer J Clin. 2007;57:190-205.

4. Kim J, Mailey B, Senthil M, et al. Disparities in gastric cancer outcomes among Asian ethnicities in the USA. Ann Surg Oncol. 2009; 16:2433-41.

5. State of Health Insurance in California: Findings from the 2003 California Health Survey. In: Edition Los Angeles: UCLA Center for Health Policy Research; 2003. 